\title{
International Congress of Scientific and Applied Photography*
}

$\mathrm{T}$ HE first International Congress of Photography was held in Paris in 1889. Congresses followed at Brussels in 1891, Paris in 1900, Liège in 1905, Brussels in 1910, Paris in 1925, London in 1928 and Dresden in 1931. It is hoped to continue the meetings triennially and the next one will probably be held in America in 1934. The recently published report of the proceedings of the eighth Congress affords a very good view of the activities of the organisation.

Standardisation of photographic sensitometry has since 1925 been one of the principal objects of the Congress. National committees for dealing with this problem have been set up in Germany, England, France and the United States. After discussions and researches lasting over three Congresses, agreement has at length been reached on a photographic unit of daylight for the testing of such materials as are to be used in daylight. The standard approaches very closely the quality of mean noon sunlight at Washington, and intensities are to be expressed in visual candles. The standard light is comparatively easy to reproduce in the laboratory since it consists in a vacuum electric lamp operating at a colour temperature of $2,360^{\circ} \mathrm{K}$. and corrected by means of a two-cell liquid filter of blue colour. The filter is one of a series worked out with great care by Messrs. Davis and Gibson of the Bureau of Standards at Washington and is easily prepared. In other details of the technique of sensitometry a series of recommendations has been drawn up. Thus the methods of obtaining the characteristic curves of photographic materials have been largely unified. The interpretation of the data is, however, not nearly so clear to define ; the real meaning of photographic 'speed' is still a matter of great difficulty. The German section of the Congress is, however, making a bold

* Bericht über den VIII Internationalen Kongress für wissenschaftliche und angewandte Photographie. Dresden, 1931. Pp. 445. Johann Ambrosius Barth, Leipzig. attempt to standardise a method for the determination of commercial speed numbers. This will be very difficult because, although the standardisation of the methods of determining characteristic curves of photographic materials is now within sight, the derivation of 'speed' numbers from the curves is still a subject of acute controversy.

For cinematography the Congress also yields opportunities for achieving international standardisation in such matters as the dimensions and spacing of sprocket holes in film, the definition of the meaning of the term 'safety film', etc.

The chief interest of the Congress lies, however, in the scientific papers presented for discussion. It is interesting to watch the growth or decline of interest in various subjects from one Congress to another. The subject of sound-recording claimed only two short communications in the Congress of 1928. At the 1931 Congress, however, eight papers of considerable scientific importance dealt with various aspects of sound-recording. In 1928 the sound film was in its infancy, by 1931 it had grown out of recognition, indeed it has been said that the number of investigators studying this subject is four times as great as the number studying all other branches of photography. The exact number may be founded mainly on guess work, but the generai truth of the statement probably stands.

For research in chemistry and physics, photography appears to serve the function of providing endless themes. It is worth noticing that several papers were communicated from various continental universities and technical institutes. Only two research papers were sent in from England; these emanated from laboratories maintained by the photographic industry. It may be suggested that workers in university laboratories would gain a great deal of inspiration by a careful study of the possibilities presented by photographic science as a field for research.

\section{Electrolysis of Boron Hydrides}

$\mathrm{N}$ a communication to the November issue of the Berichte der deutschen chemischen Gesellschaft, Herren A. Stock and E. Wiborg discuss the mechanism of the complex changes whereby substitution of hydrogen by amino-groups takes place when solutions of boron hydrides in liquid ammonia are electrolysed. Two distinct reactions have been traced, namely, one which produces hydrogen as the only gaseous product and one which results in the liberation of hydrogen at the cathode and nitrogen at the anode.

These two reactions have been studied in detail. The former predominates for a time but gradually dies down until eventually it is completely replaced by the latter. This stage is indicated by the settling down of the current to a constant minimum value. Solid substitution derivatives can be recovered from the solutions by evaporation of the solvent. These solids were hydrolysed in order to determine their composition. Analysis of the results shows that the hydrogen which is liberated in the first reaction is due principally to chemical substitution of hydrogen by amino-groups but that this substitution is initiated and maintained by electrolysis of the boron hydrides. The other reaction is ultimately due to the electro- lysis of ammonia, but as pure liquid ammonia is scarcely affected by the current, it is evident that in this case also some secondary factor has to be considered.

The authors have previously shown that boroethane, $\mathrm{B}_{2} \mathrm{H}_{6}$, acts as a dibasic acid and they are now able to trace the gradual cessation of the first or substitutionreaction to the diminution of acidity by the formation of inner salts of the amino-derivatives (after the manner of glycocoll). Some of these inner salts will still be sufficiently acidic to undergo further electrolysis and subsequent substitution, whilst others will be neutral and therefore resist further action. Thus the substitution reaction gradually fades out.

Again, the active factors in promoting the direct electrolysis of the ammonia (that is, the final reaction) are said to be the anions of the inner salts, since decomposition of ammonia is not observed in the early stages of the electrolysis. Boroethane gives rise to the compound $\mathrm{B}_{2} \mathrm{H}_{4}\left(\mathrm{NH}_{2}\right)_{2}$ as the final product of substitution.

The compounds $\mathrm{B}_{4} \mathrm{H}_{10}$ and $\mathrm{B}_{10} \mathrm{H}_{14}$ were also studied under similar conditions, when it was found that replacement of six and twelve hydrogen atoms respectively could be effected. 